\title{
Strategic Procurement, Openness and Market Structure*
}

\author{
María D. C. García-Alonso \\ University of Kent
}

Paul Levine

University of Surrey

December 4, 2007

\begin{abstract}
We examine strategic procurement behaviour by governments and its effect on market structure in sectors, such as defence and pharmaceuticals, where the government is the dominant consumer. In a world economy with trade between producer countries, and between producers and non-producers, we use a modified Dixit-Stiglitz utility function with an independent taste for variety. There is free entry and exit by firms, but by anticipating their participation constraint governments can indirectly choose the number of domestic firms and their size through its choice of procurement price. Unlike the standard model with no independent taste for variety and no external sector of non-producer countries, there are incentives for subsidies, openness impacts on industrial structure and procurement coordination between producer countries affects firm numbers.
\end{abstract}

JEL Classification: F12, H56, L10

Keywords: procurement, openness, market structure, defence and pharmaceutical sectors

\footnotetext{
*We are grateful to the ESRC for support under grant R00239388. Correspondence to p.levine@surrey.ac.uk.
} 


\section{Introduction}

Government procurement constitutes an important share of a typical country's GDP (up to $20 \%$ in some cases). In some industries, domestic government procurement is also the most important source of sales and this is clearly the case in the defence and pharmaceutical industries (see e.g., Achilladelis and Antonakis, 2001 and Kyle, 2007). As the World Trade Organization expands the restrictions over traditional protectionist trade policies, procurement practices could be used as a less obvious trade policy tool to promote strategic domestic industries. We refer to this as strategic procurement. The government's preference for maintaining a domestic provider base within 'sensitive industries' can provide a justification for strategic procurement. ${ }^{1}$

The defence industry provides a clear example of domestic firms survival directly depending on government purchasing commitments and regulatory environment (see Dunne et al., 2003). An interesting illustration of this fact is the 1993 merger wave of US military firms. ${ }^{2}$ In the pharmaceutical industry, according to Kyle (2007), in many producer countries the price for prescribed drugs to be paid by domestic health authorities is set high enough to support the local pharmaceutical industry, which is a big employer and important export earner. ${ }^{3}$ Interestingly, in both industries, there has been a recent tendency towards an increase in concentration. In the defence industry, for the top 100 firms, Dunne et al. (2003) report falls in the inverse Herfindahl index from 49 to 22, between 1990 and 1998. For the pharmaceutical industry, Matraves (1999) reports an increase in global market shares of the top 10 pharmaceutical companies from $25 \%$ to $31 \%$ between 1988 and 1995, also firms in ranked places from 11th to 20th saw increases in their market shares. Changes to procurement policies may be behind these trends. ${ }^{4}$

\footnotetext{
${ }^{1}$ The Government Procurement Agreement precludes countries from using domestic supplier preferential treatment to promote local industrial sectors. But, exceptions to the Agreement include procurement indispensable for national security or for national defence purposes.

${ }^{2}$ This was stimulated by the 'last supper' when the Pentagon Deputy Secretary Perry told a dinner of defence industry executives that they were expected to start merging. It ended when the Pentagon decided it had gone far enough and blocked the merger of Lockheed Martin with Northrop Grumman in early 1997 (Markusen and Costigan, 1999). Dunne et al. (2003) provide a detailed description of these changes.

${ }^{3}$ For the case of the UK, the Pharmaceutical Industry Competitiveness Task Force (PICTF), created in 2000 is openly aimed at ensuring that the UK remains the base for the development of new drugs.

${ }^{4}$ In a recent report, the Office of Fair Trade in the UK (OFT, 2004) argues that, in sectors such as
} 
The above mentioned industries share a number of additional characteristics which may influence procurement decisions. First, procurement authorities usually have a preference bias for the consumption of domestic goods ('home bias'), which could arise from concerns about security of supply in conflict or a desire to maintain a domestic industrial base in these sectors. Such concerns are subject to change across industry and time (see Achilladelis and Antonakis, 2001, PICTF, 2005 and NHS procurement review, 1998). Second, procurement authorities are interested in purchasing a variety of products that gives an aggregate provision of either military capability or medicines provision. Variety is important to the procurement authority so as to cover a spectrum of health and security risks. Third, there is a relatively well-established set of producer countries. Most countries cannot afford the massive $R \& D$ required to set up a major weapon systems or innovative drugs industry and, therefore, there is a small number of producer countries serving both themselves and the non-producer countries. This means that there is scope for producer countries to interact strategically.

Our main objective is to examine the impact of strategic procurement behaviour on the market structure of producer countries. More specifically, we analyze the impact that changes in home bias, taste for variety or the relative size of the non-producer market may have on procurement prices and market structure. We also study whether governments get a 'better deal' from their domestic producers, that is, whether the price paid for domestic procurement is lower or higher than the price at which domestic producers sell internationally. In addition, we investigate the potential impact of international coordination of procurement decisions on concentration. Such analysis is relevant to the industries we have in mind in this paper. As discussed by Hartley (2006), there is an ongoing debate within EU countries about the possible gains from coordinating defence procurement decisions. Different possible levels of coordination are being suggested; the lowest level would just imply a coordinated decision on domestic procurement. It is the consequence of this type of cooperation that we aim to model in our paper. There has also been an increase in the coordination in the regulation of the pharmaceutical industry in the EU which is relevant to the present paper (see Vogel, 1998).

We construct a model of strategic public procurement and international trade. There human health services and manufacture of weapons and munitions, public procurement is likely to be having an impact on market structure. 
are both producer and non-producer countries. Governments in producer countries buy products from the domestic firms and also import from the rest of the world, governments in non-producer countries cover their public procurement needs through imports. Governments endogenously determine the number of domestic firms by committing to a domestic procurement price that ensures their existence.

Our focus in this paper is the decision of the military or public health authority on how best to utilize the budgets they have, which are assumed to be exogenous. Endogeneizing the expenditure choice would be interesting, but far from straightforward. Military capability is just a component one factor in a measure of national security. The choice of how much to spend on military capability is affected by a number of factors such as the impact that this expenditure may have on the behavior of potential adversaries (see García-Alonso and Levine (2007) for a discussion). Even for the health sector, we are really only considering medicines provision; a complete measure of health provision would include many other factors such as numbers of GPs, preventive health, etc. which we do not analyze in this paper.

An important feature of our model is the existence of producer and non-producer countries. A big domestic market and strong home bias (see Levine et al., 2000) may affect governments decision to initially support a domestic industry. Other factors, such as export controls, limit the access that importer countries have to sensitive military technologies. Also, regulations on prices and patents are important determinants of why some countries may become drug producers (see Achilladelis and Antonakis, 2001). However, our model does not aim to explain the reasons for countries to become producers; that is, we take the producer or non-producer status as given.

The interaction between the procurement authorities across countries and firms is modelled as a four-stage game with a subgame perfect equilibrium (henceforth, SPE). First, given the procurement budget, producer governments choose the volume and price of domestically procured goods. Second, given procurement decisions firms enter or leave the sector. Third, firms in producer countries simultaneously compete in export prices and finally, governments in both producer and non-producer countries procure imports. We then use backwards induction to find the SPE.

In a standard Dixit-Stiglitz monopolistic competition model of trade only involving 
producers (see Dixit and Stiglitz, 1977), the procurement price turns out to be the world market price, the bias for domestic rather than imported procured goods, the inverse of 'openness' in our terminology, has no effect on market structure and the non-cooperative procurement equilibrium is efficient (from the viewpoint of producers). As a result of two features of our model, these results no longer hold: first, the existence of an external market of non-producers importing goods from producers and second, we use a modified DixitStiglitz utility function as in Benassy (1996) to incorporate a taste for variety effect that is independent of the elasticity of substitution. The latter allows the choice as to whether to procure an additional variety to be different from the choice of quantity procured.

In this paper, we find that the price that procurement authorities pay to their domestic firms may be higher or lower than the imports price. Procurement authorities are more likely to 'overpay' their domestic firms if they have a high taste for variety and the external market is relatively small.

In addition, we show that an increase in openness, a reduction in taste for variety and an increase in the relative size of the external market reduce the number of firms in equilibrium. This result provides a theoretical explanation for the recent increases in concentration in both the defence and the pharmaceutical industry. Increased development costs and a reduction in health and military budgets may be among the other factors determining such trends (see Achilladelis and Antonakis, 2001).

Our paper also shows that cooperation between the governments of producer countries in setting procurement policies affects firm numbers. Such impact will depend on the size of the external market and the additional taste for variety effect. For instance, with a non-producer fringe but, no additional taste for variety factor, cooperation would lead to an increase in concentration. For the case of no external market but, additional taste for variety factor, the opposite holds.

Our research is linked to a branch of the procurement and trade literature starting with Baldwin (1970). ${ }^{5}$ This literature studies the impact of unilaterally home-biased

\footnotetext{
${ }^{5} \mathrm{~A}$ second branch of the procurement literature focuses on the interaction between firms and procurer in a environment characterized by the existence of asymmetric information (examples of that literature are McAfee and McMillan, 1989, Anton and Yao, 1992, Laffont and Tirole, 1993, Branco, 1994, McGuire and Riordan, 1995 and, Vagstad, 1995). Our paper abstracts from such issues. A third strand analyzes the interaction between domestic defence procurement and firm competition for international arms trade
} 
procurement on the patterns of international specialization. Baldwin $(1970,1984)$ shows that a unilateral home bias in favour of domestic producers is inconsequential to the patterns of specialization under the assumption of perfect competition. Later papers prove that this neutrality result does not necessarily hold with imperfect competition. Brulhart and Trionfetti (2004) prove that if a country has a unilateral home bias towards a domestic monopolistic sector, it will also have more firms in that sector relative to the other country (see e.g., Miyagiwa (1991) for impact on trade volumes).

Our framework differs from this literature in a number of aspects. Brulhart and Trionfetti (2004) consider a general equilibrium model in which there is both private consumption and public procurement. Government's bias in favor of domestically produced goods means that a given proportion of government purchases are reserved to domestic producers (a higher proportion means a higher home bias). In our paper, there is no private demand. Also, we have a multiple stage game where governments foresee the impact that their domestic procurement decisions have on firm numbers. In order to make this model more tractable, we use a partial equilibrium model which focuses on the simultaneous decisions of the procurement authorities across countries, each with an exogenous procurement budget. However, unlike Brulhart and Trionfetti (2004), we allow for the existence of a group of non-producer countries and we generalize the standard Dixit-Stiglitz preferences to include an additional like-for-variety element as in Benassy (1996). Given the differences between the two papers, comparing them is not straightforward. Using the symmetric general equilibrium as the baseline, they analyze the impact of a unilateral change in home bias on specialization. In that case, monopolistic competition with DixitStiglitz preferences are enough to make changes in home bias affect the number domestic firms relative to total firm numbers across the world. Whilst their focus is to analyze the impact of asymmetric changes in home bias on international specialization (domestic number of firms relative to the rest of the world), our comparable objective is to analyze the impact of a symmetric multilateral change in home bias across producers on the absolute numbers of firms. For the standard Dixit-Stiglitz preferences, we show that this would not have an impact on total firm numbers. When the additional like-for-variety element or the external producer market are introduced, more home bias will lead to an increase (see e.g., Levine and Smith, 2000, García-Alonso, 1999, 2000 and Levine, Mouzakis and Smith, 2000). However, this literature considers market structure as exogenous. 
in the number of firms. Interestingly, in the cooperative case, the optimal number of firms is independent of home bias.

The present paper is specifically designed to capture government home bias. In a separate paper (Coto-Martínez, García-Alonso and Levine (2005)), we develop a model in which the bias lies within the private consumers. In that paper, there is no government procurement, only private consumption. Although a parallel could be established between the two papers, the modeling requirements are quite different. Even if there is a home bias, with private consumers one must ensure that the international price arbitrage conditions are met. Also, since there is only private consumption, governments have different policy instruments such as domestic consumption subsidy, imports tariff and a fixed cost subsidy to the domestic firms. In the present paper, we focus on the impact that government procurement decisions alone have on industry structure.

The rest of the paper is organized as follows. Section 2 provides the basic set-up and the sequence of moves in the procurement game with governments and firms as players. Section 3 solves the SPE with non-cooperative at the procurement stage one of the game. Section 4 studies the cooperative procurement equilibrium at stage one and compares it with the non-cooperative equilibrium. Section 5 provides some concluding remarks. Detailed proofs of Propositions can be found in García-Alonso and Levine (2005). ${ }^{6}$

\section{The Set-up}

\subsection{The Model}

We model an international market for a public service good, consisting of $\ell$ producing and importing countries and $r$ non-producers who only import. The total budget in each country available for this particular public service good is given. ${ }^{7}$ Producer country 1

\footnotetext{
${ }^{6}$ The earlier working paper version of this paper, García-Alonso and Levine (2005) also provides results on the case where firms engage in strategic pricing. Dunne et al. (2007) adopts a similar framework to examine the defence sector in an international market for arms where importing countries are engaged in regional arms races.

${ }^{7} \mathrm{~A}$ constant share of GDP is devoted to defence or health can be defended as a realistic assumption, but as is typical in the literature one could start with a national welfare function of the form $U=U\left(C, C_{0}\right)$ where $C$ is Dixit-Stiglitz index representing the output of a public service obtained from differentiated inputs ((1) below) and $C_{0}$ is a numeraire good which in this context is remaining consumption. If the
} 
produces differentiated goods $j=1,2, \cdots, n_{1}$, country 2 produces goods $j=n_{1}+1, n_{1}+$ $2, \cdots, n_{1}+n_{2}$, etc., so there are $\sum_{i=1}^{\ell} n_{i}=N$, say, goods in total. Governments procure from domestic firms (if they exist) and overseas firms who enter or exit the market freely.

It makes for a simpler presentation if we focus on decisions in producer country 1 . Government 1 procures $d_{1 j}, j=1,2, \cdots, n_{1}$ domestically produced goods and $m_{1 j}, j=$ $n_{1}+1, n_{1}+2, \cdot \cdot, N$ imported goods. The government utility takes the form of a generalized Dixit-Stiglitz CES function

$U_{1}=\left[w_{1} n_{1}+\left(1-w_{1}\right)\left(N-n_{1}\right)\right]^{\nu}\left[w_{1} \sum_{j=1}^{n_{1}}\left(d_{1 j}\right)^{\alpha}+\left(1-w_{1}\right) \sum_{j=n_{1}+1}^{N}\left(m_{1 j}\right)^{\alpha}\right]^{\frac{1}{\alpha}} ; \alpha \in[0,1), \nu>0$

In (1) the elasticity of substitution between all goods whether produced domestically or imported is given by $\sigma=\frac{1}{1-\alpha}>1.8$ The weights $w_{1}$ and $1-w_{1}$, with $w_{1} \in\left[\frac{1}{2}, 1\right]$, express the bias for domestic rather than imported procurement in country 1 . If $w_{1}=\frac{1}{2}$, there is no bias and at the other extreme if $w_{1}=1$, there is autarky between producers. Thus in this set-up we can regard $1-w_{1}$ as a measure of openness. ${ }^{9}$

If we put $\nu=0$ and $w_{1}=\frac{1}{2}$, (1) reduces to the standard Dixit-Stiglitz utility function, which is now commonplace in the new open macro-economy, new trade and endogenous growth literatures. But, as Benassy (1996) points out, this form of utility is restricted in that it implies a one-to-one correspondence between the taste for variety and the elasticity of substitution. To see the significance of this generalized form of the Dixit-Stiglitz utility function, suppose there are two producer countries. Consider a certain amount of total output $y$ spread out between $w_{1} y$ units of a single variety in country 1 and $\left(1-w_{1}\right) y$ of a

sector in question is defence then $C$ would be military security; if the sector is pharmaceuticals, then $C$ would be public health. If the utility is Cobb-Douglas (a standard assumption) then the expenditure on the public service is constant and the model reduces to the one in this paper.

${ }^{8}$ In the military context one can think of goods as types of planes, battle ships etc with the same inter-type and intra-type, inter-country and intra-country elasticities of substitution. This is a standard assumption in the new trade literature and new open economy macroeconomics. It is possible to extend the analysis to allow for different inter and intra-type and country elasticities, but at an inevitable cost in terms of tractability.

${ }^{9}$ Note that(1) can be given an 'iceberg' technology interpretation by writing it as $U_{1}=\left[w_{1} n_{1}+(1-\right.$ $\left.\left.w_{1}\right)\left(N-n_{1}\right)\right]^{\nu}\left[\sum_{j=1}^{n_{1}}\left(d_{1 j}\right)^{\alpha}+\sum_{j=n_{1}+1}^{N}\left(T_{1} m_{1 j}\right)^{\alpha}\right]^{\frac{1}{\alpha}}$, where $T_{1}=\left(\frac{1-w_{1}}{w_{1}}\right)^{\frac{1}{\alpha}}$ is the fraction of the original good that actually arrives, the rest 'melting away' on route. However, our model does not endogeneize the reasons for the home bias. 
single variety in country 2 . From (1), this will yield utility $U_{1}=1^{\nu}\left[w_{1} y^{\alpha}+\left(1-w_{1}\right) y^{\alpha}\right]^{\frac{1}{\alpha}}=y$ by the constant returns to scale property of our utility function.

Now let us define a function $v_{1}\left(n_{1}, n_{2}\right)$ to represent the proportional utility gain from spreading this output $y$ between all $N=n_{1}+n_{2}$ varieties rather than concentrated on a proportion $w_{1}$ on one variety in country 1 and a proportion $1-w_{1}$ on one imported variety as before. Again, from (1), we can then express $v_{1}\left(n_{1}, n_{2}\right)$ as

$$
\begin{aligned}
v_{1}\left(n_{1}, n_{2}\right) & =\frac{\left[w_{1} n_{1}+\left(1-w_{1}\right) n_{2}\right]^{\nu}\left[w_{1} \sum_{j=1}^{n_{1}}\left(\frac{y}{N}\right)^{\alpha}+\left(1-w_{1}\right) \sum_{j=1}^{n_{2}}\left(\frac{y}{N}\right)^{\alpha}\right]^{\frac{1}{\alpha}}}{y} \\
& =\frac{\left[w_{1} n_{1}+\left(1-w_{1}\right) n_{2}\right]^{\nu+\frac{1}{\alpha}}}{N}
\end{aligned}
$$

Suppose that the total number of varieties $N=n_{1}+n_{2}$ increases, keeping the proportion $\frac{n_{1}}{n_{2}}$ fixed. Then, putting $n_{1}=k N$ and $n_{2}=(1-k) N, v_{1}=v_{1}(N)=\left[w_{1} k+\left(1-w_{1}\right)(1-\right.$ $k)]^{\left(\frac{1}{\alpha}+\nu\right)} N^{\left(\nu+\frac{1}{\alpha}-1\right)}$. We now define the taste for variety by the elasticity $\frac{N d v_{1}}{v_{1} d N}=\tau$ say, given by $\tau=\frac{N d v_{1}}{v_{1} d N}=\nu+\frac{1}{\alpha}-1$. The significance of the extra term in (1) now becomes apparent. If $\nu=0$, then the taste for variety $\tau=\frac{1}{\sigma-1}$ which is determined solely by the elasticity of substitution. Thus, the standard Dixit-Stiglitz formulation establishes an arbitrary link between fundamentally different concepts: taste for variety and elasticity of substitution, the latter, as we shall see, also determining the market power. Introducing the extra $\nu$ term breaks this link and has important consequences for the subsequent analysis.

Governments in producer countries procure from domestic and foreign firms, possibly at different prices. Let $p_{1 j}$ be the price of the procured domestic good and $P_{j}$ be the world market price of the traded good of variety $j$ produced by firms in all producing countries $j=1,2, \cdot \cdot, N$. Then, the budget constraint for government in producer country 1 is

$$
\sum_{j=1}^{n_{1}} p_{1 j} d_{1 j}+\sum_{j=n_{1}+1}^{N} P_{j} m_{1 j}=G_{1}
$$

where $G_{i}$ is total procurement expenditure in country $i$.

For the non-producing country $i=\ell+1, \ell+2, \cdots, \ell+r$ utility is given by

$$
U_{i}=N^{\nu}\left[\sum_{j=1}^{N}\left(m_{i j}\right)^{\alpha}\right]^{\frac{1}{\alpha}}
$$

and their budget constraint is given by $(2)$ with $n_{1}=0$. 
The model is completed by specifying the cost structure for the firm. Firm $j$ in producer country 1 produces $d_{1 j}$ units of variety $j$ for its domestic government at a procurement price $p_{1 j}$ and exports $x_{1 j}$ units at an international market price $P_{j}$. The cost of producing total output $y_{1 j}=d_{1 j}+x_{1 j}$ is assumed to be

$$
C\left(y_{1 j}\right)=F+c y_{1 j}
$$

We associate the first term in (4) with fixed capital costs and R\&D, the final term constitutes variable costs. It follows that the profit of this firm is

$$
\pi_{1 j}=p_{1 j} d_{1 j}+P_{j} x_{1 j}-C\left(y_{1 j}\right)
$$

Finally, since there is free entry and exit, we must impose the participation constraint $\pi_{1 j} \geq 0$.

\subsection{Sequencing of Events}

We first consider the optimal decisions of a single government taking the decisions of other governments as given. The sequencing of events is as follows:

1. Domestic Procurement by Producer Governments. Given total procurement expenditure, the government in producer country 1 procures domestic goods of quantity $d_{1 j}$ at price $p_{1 j}$, for $j=1,2, \cdots, n_{1}$ given imports decided at stage $4, m_{1 j}, j=n_{1}+1, n_{1}+2, \cdots, N$ at the world market equilibrium price $P_{j}$. All decisions are subject to a budget constraint and a non-negative profit participation constraint for domestic firms.

2. Free Entry and Exit by Firms. Given the procurement decision firms enter or leave the sector. ${ }^{10}$

3. Price-Setting. With a commitment to producing $d_{1 j}$, in a price-setting equilibrium of this stage of the game, firms in producer country 1 set world prices $P_{j}$ and export quantity $x_{1 j}$ to countries $i=2, \cdots, \ell+r$.

4. Demand for Imports. Given the world market price $P_{j}$, and procurement expenditure, governments in both producer and non-producer countries $i=1,2, \cdots, \ell+r$ procure imports of good, $m_{i j}, j=1,2, \cdots, N$, where $i \neq j$ for producer countries $i=1,2, \cdots, \ell$.

\footnotetext{
${ }^{10}$ The procurement price may be greater or less than the international market price. Firms already participating in the international market will accept domestic procurement as long as the procurement price exceeds the marginal cost.
} 


\section{The Non-Cooperative Procurement Equilibrium}

We now solve for the non-cooperative SPE in which governments in producer countries make procurement decisions at stage one independently. ${ }^{11}$ We proceed by backward induction starting at stage 4 .

\subsection{The Imports Decision at Stage 4}

At stage 4 , given the price $P_{j}$, and the number of differentiated goods, the government in producer country $i=1,2, \cdots, \ell$ chooses how much to import of each foreign variety $m_{i j}$, to maximize utility given by (1) subject to its budget constraint (2) where the procurement element is given. Using standard constrained optimization procedures, we get the import demand for any good $j=1,2, \cdots, N$

$$
\begin{aligned}
m_{i j} & =\frac{\left[G_{i}-\sum_{j=n_{i-1}+1}^{n_{i-1}+n_{i}} p_{i j} d_{i j}\right]}{P_{j}^{\sigma} \sum_{k \neq\left[N_{i-1}, N_{i}\right]}^{N} P_{k}^{1-\sigma}} ; j \neq N_{i-1}+1, N_{i-1}+2, \cdots, N_{i-1}+n_{i} \\
& =0 ; \quad j=N_{i-1}+1, N_{i-1}+2, \cdots, N_{i-1}+n_{i}
\end{aligned}
$$

where we have defined $N_{i}=n_{1}+n_{2}+\cdots+n_{i}$ for $i \geq 1$ (in which case $N_{1}=n_{1}$ and $\left.N_{\ell}=N\right) .{ }^{12}$ We can define a price index of imported goods for producer countries as $\hat{P}_{i}=\left(\tilde{P}_{i}\right)^{\frac{1}{1-\sigma}}$ where

$$
\tilde{P}_{i}=\sum_{k \neq\left[N_{i-1}, N_{i}\right]}^{N} P_{k}^{1-\sigma} ; i=1,2, \cdots, \ell
$$

The analysis for non-producer countries is standard and results in a demand by government $i=\ell+1, \ell+2, \cdots, \ell+r$ for good $j=1,2, \cdots, N$

$$
m_{i j}=\frac{G_{i}}{P_{j}^{\sigma} \tilde{P}}
$$

where $\tilde{P}=\sum_{k=1}^{N} P_{k}^{1-\sigma}$. Note that $\hat{P}=\tilde{P}^{\frac{1}{1-\sigma}}$ is the analogous price index of imported goods facing each non-producer country (see, for example, Beath and Katsoulacos, 1991).

\footnotetext{
${ }^{11}$ Note that in the absence of procurement considerations at stage 1 , the trade equilibrium from stage 2 onwards corresponds exactly to a standard trade model, see for example Krugman, 1979.

${ }^{12}$ Thus, country $i=1,2, \cdot \cdot, \ell$ produces varieties $j=N_{i-1}+1, N_{i-1}+2, \cdots, N_{i-1}+n_{i}=N_{i}$ and imports $m_{i j}$ units of variety $j=1,2, \cdots, N_{i-1}, N_{i}+1, N_{i}+2, \cdots, N$ (defining $N_{0}=0$ ).
} 


\subsection{Price Setting at Stage 3}

Proceeding to stage 3 of the game, in producer country 1 firm $j=1,2, \cdots, n_{1}$ profit is given by

$$
\pi_{1 j}=\left(p_{1 j}-c\right) d_{1 j}+\left(P_{j}-c\right) x_{1 j}-F ; j=1,2, \cdots, n_{1}
$$

where exports to producers and non-producers are given by

$$
x_{1 j}=\sum_{i=2}^{\ell+r} m_{i j}=\sum_{i=1}^{\ell} \frac{\left[G_{i}-\sum_{j=n_{i-1}+1}^{n_{i-1}+n_{i}} p_{i j} d_{i j}\right]}{P_{j}^{\sigma} \tilde{P}_{i}}+\sum_{i=\ell+1}^{\ell+r} \frac{G_{i}}{P_{j}^{\sigma} \tilde{P}}
$$

The first term in (9) consists of exports to other producing countries and depends on the procurement decisions already taken at stage 1 and on all prices set at this stage 3 of the game. The second term consists of exports to non-producing countries and again depends on the all prices set by firms at stage 3 of the game.

Profit maximization results in the usual Lerner Index for any variety $j \in\left[1, n_{1}\right]$ in country $i$

$$
L_{i}=\frac{P_{i}-c}{P_{i}}=\frac{1}{\sigma}
$$

\subsection{The Procurement Decision at Stage 1}

We complete the equilibrium by evaluating the optimal decision of the government in country 1 at the procurement stage of the game. In fact, stages 1 and 2 can be considered together. The government when choosing the procurement price, $p_{1}$, relaxes or tightens the firms' participation constraint and, in effect, chooses the number of domestic firms. Imposing symmetry between identical domestic firms, procurement quantity will be the same, $d_{1 j}=d_{1}$ say, for all domestic varieties. Moreover, given the symmetry between all firms within each country $i=2,3, \cdots, \ell$ in the international market, government 1 will choose the same amount of imports of each variety from country $i, m_{1 i}$ say. We examine the Nash equilibrium of stage 1 of the game and the SPE of the whole game. The optimization problem of the government in country 1 is to maximize utility

$$
U_{1}=\left[w_{1} n_{1}+\left(1-w_{1}\right)\left(N-n_{1}\right)\right]^{\nu}\left[w_{1} n_{1} d_{1}^{\alpha}+\left(1-w_{1}\right) \sum_{i=2}^{\ell} n_{i} m_{1 i}^{\alpha}\right]^{\frac{1}{\alpha}}
$$


with respect to independent choice variables $d_{1}$ and $n_{1},{ }^{13}$ given the world prices $P_{i}=P=$ $\frac{c}{\alpha}$ of each variety from country $i$, the corresponding decisions of other countries, and two constraints. These are the budget constraint $\left(B C_{1}\right)$ and the representative domestic firm's participation constraint $\left(P C_{1}\right)$ given by

$$
\begin{array}{ll}
B C_{1}: & p_{1} n_{1} d_{1}+\sum_{i=2}^{\ell} P_{i} n_{i} m_{1 i}=G_{1} \\
P C_{1} & : \quad \pi_{1}=\left(p_{1}-c\right) d_{1}+\left(P_{1}-c\right) x_{1}-F \geq 0
\end{array}
$$

Clearly the participation constraint must bind so the procurement price is given by

$$
p_{1}=c+\frac{F-R\left(x_{1}\right)}{d_{1}}
$$

where we have written net export revenue $\left(P_{1}-c\right) x_{1}=R\left(x_{1}\right)$. It is useful to note that exports $x_{1}=x_{1 j}$ of each home variety $j$ can be written in terms of decision variables as the sum of exports to other producers $\left(x_{1}^{p}\right)$ and to non-producers $\left(x_{1}^{n p}\right)$ as follows:

$$
\begin{aligned}
x_{1} & =\sum_{i=2}^{\ell+r} m_{i}=\sum_{i=2}^{\ell} m_{i}+\sum_{i=\ell+1}^{\ell+r} \frac{G_{i}}{P\left(n_{1}+n_{2}+\cdots+n_{\ell}\right)} \\
& =x_{1}^{p}+x_{1}^{n p}
\end{aligned}
$$

Since we are assuming a Nash equilibrium in independent decision variables $d_{1}$ and $n_{1}$ at stage 1 , we can eliminate the procurement price $p_{1}$ using the $P C_{1}$ constraint. It is then apparent that the payment to the firm can also be treated as a lump sum of amount $p_{1} d_{1}$.

The symmetric non-cooperative procurement equilibrium under monopolistic competition can then be obtained using standard constrained optimization techniques. Two closely related results presented below follow. The first result, presented in Proposition 1 explains how the domestic procurement price will compare to the world market price. Proposition 2 discusses how changes in some of the model's parameters will affect firm numbers.

\footnotetext{
${ }^{13}$ Any two from four possible decision variables, $d_{1}, m_{1}, p_{1}$ and $n_{1}$ can be assumed, but will lead to different Nash equilibria. Our particular choice, $d_{1}$, and $n_{1}$ is made partly, for analytical convenience, but can be also justified by the need to observe decision variables in a more realistic incomplete information setting, where the process of dynamic adjustment towards the equilibrium, for example of a Cournot-type, needs to be addressed. It is plausible to assume that the domestic procurement decision, $d_{i}$, and the number of firms supported, $n_{i}, i=1,2, \cdots, \ell$ are more readily observed than the procurement price, $p_{i}$, $i=1,2, \cdots, \ell$, which involves a possibly hidden subsidy.
} 


\section{Proposition 1: The Procurement Price}

In a symmetric, non-cooperative procurement equilibrium, the procurement price may be above or below the world market price. A high taste for variety encourages the former and a large external market encourages the latter.

Proposition 2: The Number of Firms

In a symmetric, non-cooperative equilibrium the number of firms increases as the taste for variety by producer countries increases. An increase in openness, in the form of a reduction in preferences of producer countries for domestic supply (home bias), and an increase in the relative size of the external market results in a decrease in the number of firms.

In a 'traditional' Dixit-Stiglitz utility function where $\nu=0$ and in the limit as the external market becomes small (but still of sufficient size to determine the world market price), we have that the procurement price equals the market price. In our more general model, the procurement price can be above or below the world market price. ${ }^{14}$ A high taste for variety $\nu$ encourages the former. The government then supports more domestic firms, each producing a single variety, and will pay a higher procurement price to achieve this. The intuition behind the external market effect in these two propositions is that an increase in the net export revenue relaxes the firms' participation constraints for a given number of incumbents. This then enables governments to procure the same number of varieties at a lower procurement price. In the non-cooperative procurement equilibrium, each government takes into account only its own contribution to the world supply of differentiated goods and, through reducing the procurement price, it lowers its optimal number of domestic firms as the external market becomes more important. ${ }^{15}$

One would think that one of the advantages of having a domestic sector from whom

\footnotetext{
${ }^{14}$ Note that as long as $p>c$, the firm having incurred the fixed cost of entry will benefit from the procurement contract and in a free-entry equilibrium of identical firms, those relying only on the export market will not be able to survive. Thus, through the procurement process, the government can choose the number of firms in equilibrium.

${ }^{15}$ Note that, in a traditional monopolistic competition model (see Krugman (1979)), when economies open to trade (with other symmetric economies), the number of domestically produced varieties does not change. In this paper, a reduction in home bias can be seen as an increase in openness. However, changes to home bias do affect domestic firm numbers.
} 
to procure goods should be to allow the domestic procurement authorities to pay a price for domestic procurement that is lower than the price at which domestic producers sell internationally. Our price result actually proves that this is not necessarily the case. Evidence from the military industry seems to suggest that the price charged to the domestic government may actually be higher than the exports price (see (Chalmers et al. (2002)). In the pharmaceutical industry, a more liberal method of price regulation may allow firms to price their drugs at a higher level domestically. ${ }^{16}$ Interestingly, within the context of our model, this would be explained by a strong independent love for variety and home bias, effects that dominate those of the external market.

It is tempting to establish parallels between our model and the Strategic Trade Literature result that states that the optimal strategic policy for firms competing in prices for the exports market is to impose an exports tax so as to induce higher prices and therefore higher profits. An immediate comparison cannot be made though. In our model, procurement decisions are taken before firms compete for the exports market and can be seen as a lump sum transfer to the firms. Although firm numbers are affected by the procurement transfer, in our monopolistic competition framework, international prices do not depend on firm numbers and therefore, procurement policies do not affect international prices directly or indirectly. ${ }^{17}$

Turning to proposition 2, this result is consistent with the result on prices. The procurement authority uses commitments to procurement volumes and prices as a means to determine firm numbers. Less home bias will naturally decrease firm numbers as authorities become less interested in procuring domestic varieties, a similar thing happens with less independent love for variety. Finally, a relatively bigger external market will change the focus of the procurement authority towards ensuring that the exports market contributes as much as possible to sustain the production of new varieties. Data seems to show that concentration has risen in both military and drug industry to which this model

\footnotetext{
${ }^{16}$ For the UK case, the Pharmaceutical Industry Task Force (2005) explicitly states that prices of onpatent medicines are on average towards the top end of European prices, although lower than US prices, this is presented as a competitiveness indicator and justified by the need to contribute to the development costs of new medicines.

${ }^{17}$ If we allowed for strategic pricing, the impact of the relative size of the external market is stronger, the reason for this is that the international price now depends on firm numbers and the lower transfer encourages less firms and therefore higher international prices (see Garcia-Alonso and Levine (2005)).
} 
applies best. Achilladelis and Antonakis (2001) mention trade liberalization, increasing development costs and time lags for introduction of new drugs, and a contraction in public support for health care insurance as some of the reasons behind the 1980s-90s merger wave in the pharmaceutical industry. The above result suggests that an increase in the relative importance of external markets and less home bias (more openness) could also be behind these changes. A willingness to procure from abroad, 'openness' in our terminology, and the growing relative size of the international market of non-producers as production becomes more concentrated are two features one may associate with 'globalization'. In that sense we may conclude that our results suggest these aspects of globalization will result in a decrease in the number of firms in the world market.

\section{Procurement Cooperation Between Producer Governments}

Up to this point, we have examined the SPE equilibrium of a game in which stage 1 is a non-cooperative Nash equilibrium in procurement decisions. This section examines what happens if these decisions are made jointly in a cooperative equilibrium at stage 1. We pose this question in the context of the current discussion on possible ways to improve cooperation in procurement policies for the defence and pharmaceutical industries in the EU. Our objective in this section is to analyze the effect of such cooperation on firm numbers. Since firms are identical in their cost structures, we can impose symmetry. Then, in a symmetric cooperative procurement agreement at stage $1, \ell$ identical producers would jointly choose $d_{1}=d_{2}=\cdots=d_{\ell}=d, n_{1}=n_{2}=\cdots=n_{\ell}=n$ to maximize $U_{1}=U_{2}=\cdots=U_{\ell}=U$ subject to budget and participation constraints. This leads to the following result:

\section{Proposition 3: Optimal Cooperative Procurement}

In the optimal cooperative procurement arrangement, the total number of firms is independent of the preferences of producer countries for domestic supply. As with the non-cooperative equilibrium, an increase in the relative size of the external market leads to a lower total number of firms under cooperation.

The independence of firm number on preferences contrasts with the non-cooperative 
equilibrium where an decrease in bias, $w$, leads to a decrease in the total number of firms (see proposition 2). The reason for this is that, under cooperation, bias between countries is internalized and the overall effect on the outcome cancels out. As with non-cooperation, the external revenue lowers the procurement price required to secure the participation of each firm. By sharing the fixed total demand in the external market over a smaller number of firms in total, cooperating procuring governments can reduce the procurement cost. The greater the size of the external market, the greater this effect is.

Now let us compare the cooperative and non-cooperative outcomes. We are particularly interested in the numbers of firms and whether cooperation contributes to the observed increase in concentration. Denote the firm number per country in the cooperative and non-cooperative equilibria by $n^{C}$ and $n^{N C}$ respectively. We then have the following result:

\section{Proposition 4. Comparison of Cooperative and Non-Cooperative Equilibria}

Comparing the cooperative and non-cooperative procurement equilibria with no external market, taste for variety $(\nu>0)$ results in $n^{N C}<n^{C}$; i.e., less firms in the non-cooperative equilibrium. If $\nu=0$ competition in the external market results in $n^{N C}>n^{C}$; i.e., more firms in the non-cooperative equilibrium.

In the case of no taste for variety and no external market $(\nu=r=0)$, we arrive to the familiar Dixit-Stiglitz result that cooperation results in the same number of firms as non-cooperation $\left(n^{N C}=n^{C}\right)$. If $\nu>0$, but, there is no external market, the noncooperative equilibrium is inefficient: each country fails to internalize the external benefit to other countries from producing variety and as a result, too few varieties are produced; i.e., $n^{N C}<n^{C}$.

When there is an external market but the Dixit-Stiglitz utility function is conventional $(\nu=0)$, the opposite is true: $n^{C}<n^{N C}$. Now the non-cooperative equilibrium is again inefficient but this time there are too many varieties produced compared with the efficient (from the viewpoint of producers) cooperative equilibrium. The reason for this is that given that total demand is fixed, competition for the external market sees revenue per firm from external exports rise as the total number of firms falls. This occurs because firms then compete less intensively and can spread their fixed costs over a larger market 
share. Under non-cooperation, fixed costs in each country are only spread over domestic varieties whereas under cooperation governments collude to spread such costs over all varieties. This results in an incentive to reduce the number of varieties still further. ${ }^{18}$

\section{Conclusions}

This paper has explored the strategic procurement behaviour by governments who can, in effect, choose the number of firms and their size by adjusting the procurement price. In a standard Dixit-Stiglitz monopolistic competition model where all countries are producers, the procurement price coincides with the world market price, openness has no effect on market structure and cooperation between producer governments does not affect firm numbers. With an external market and a modified Dixit-Stiglitz utility function to incorporate a taste for variety effect, this is no longer the case.

In a symmetric, non-cooperative equilibrium, the number of firms is influenced by a number of factors. We show that number of firms increases as the taste for variety by producer countries increases. In addition, an increase in openness, in the form of a reduction in preferences of producer countries for domestic supply, and an increase in the relative size of the external market, results in a decrease in the number of firms and therefore an increase in concentration.

We also show that producer government cooperation in procurement decisions may now affect firm numbers. For example, for a large external market, coordination would lead to more concentration.

The main implication of our results is that the marked increase in concentration in the military sectors of the US and the EU can be explained by a increase in openness and the increased importance of the external sector of arms importers. To some extent, this also helps to explain concentration trends in the pharmaceutical industry.

In addition, our result on the impact of cooperation in procurement decisions on firm numbers is specially relevant to the military industry in the EU context where different levels of cooperation in military procurement are being discussed (Hartley (2006) discusses current proposals for cooperation in the military industry).

\footnotetext{
${ }^{18}$ With strategic pricing by firms, this raises the price countries receive from the external market and the incentive to reduce the number of firms is strengthened (see García-Alonso and Levine, 2005).
} 
Our paper makes a number of simplifying assumptions that allow us to use a model specification that can be applied to a number of industries: home bias is exogenous, we only analyze the symmetric equilibrium, we do not endogeneize the decision of countries to become producers or non-producers and procurement budgets are exogenous. As already discussed, the motivation of the home bias may change across industries and also across time and therefore, it is not easy to endogeneize whilst keeping the generality of the model. The focus on the symmetric equilibrium is made to help us obtain explicit results (Brulhart and Trionfetti (2001) analyze the asymmetric case for the standard Dixit-Stiglitz framework). Also, endogeneizing the government's decisions on the size of the procurement budget would again require us to make assumptions on the government's objective function. These would include the more complex decision on how much national security or health to provide; we just focus our analysis on military capability and pharmaceuticals provision which are only elements of national security and health provision. Similar issues arise when endogeneizing the decisions of countries to be producers or non-producers.

The above issues have been partially addressed in the defence and health literatures. Our paper presents a simple analysis of the impact of government procurement policies on market structure and prices. Finally, the regulation of the industries that motivate our paper tends to be quite elaborate and contains other elements that may affect industry structure. For instance, in the case of the pharmaceutical industry, price regulation of medicines is complex and varies across countries. For the military industry other policies such as export controls influence the market structure. Our paper aims to present a simple model that may encompasses the idea that government's monopsony power can have an impact on market structure that is applicable to at least these two industries.

\section{References}

Achilladelis, B. and Antonakis, N. (2001) The dynamics of technological innovation: the case of the pharmaceutical industry. Research Policy, 30, 535-588.

Anton, J. and Yao, D. (1992) Coordination in split award auctions. Quarterly Journal of Economics, 30, 538-552.

Baldwin, R. E. (1970) Nontariff Distortions of International Trade. Brookings Institu- 
tion, Washington, D. C.

Baldwin, R. E. (1984) Trade Policies in Developed Countries. R. W. Jones and P. B. Kenen, eds., Handbook of International Economics, Vol. 1, Amsterdam: NorthHolland.

Beath, J. and Katsoulacos, Y. (1991) The Economic Theory of Product Differentiation, Cambridge University Press.

Benassy, J. P. (1996) Taste for variety and optimum production patterns in monopolistic competition. Economic Letters, 52, 41-47.

Branco, F. (1994) Favouring domestic firms in procurement contracts. Journal of International Economics, 37, 65-80.

Brulhart, M. and Trionfetti, F. (2004) Public expenditure, international specialization and agglomeration. European Economic Review, 48, 851-881.

Coto-Martínez, J., García-Alonso, M. C. and Levine, P. (2005) Taste for variety and optimum product diversity in an open economy, University of Kent, Discussion Paper No. $05 / 08$.

Dixit, A. K. and Stiglitz, J. E. (1977) Monopolistic competition and optimal product diversity. American Economic Review, 67(3), 297-308.

Dunne, J. P., García-Alonso, M. C., Levine, P. and Smith, R. P. (2003) Concentration in the international arms industry. University of the West of England Discussion Paper No. 03/01.

Dunne, J. P., García-Alonso, M. C., Levine, P. and Smith, R. P. (2007) Determining the defence industrial base. Defence and Peace Economics, 18(3), 199-221.

García-Alonso, M. C. (1999) Price competition in a model of the arms trade. Defence and Peace Economics, 10(3), 273-303.

García-Alonso, M. C. (2000) The role of technology in a model of horizontal differentiation. International Journal of Industrial Economics, 18(5), 747-773. 
García-Alonso, M. C. and Levine, P. (2005) Strategic procurement, openness and market structure, University of Kent, Discussion Paper No. 05/03.

García-Alonso, M. C. and Levine, P. (2007) Arms trade and arms races: a strategic analysis. Handbook of Defence Economics II, Keith Hartley and Todd Sandler eds., North Holland, Series in Economic Handbooks.

Hartley, K. (2006) Defence industrial policy in a military alliance. Journal of Peace Research, 43(4), 473-489.

Krugman, P. R. (1979) Increasing returns, monopolistic competition, and international trade. Journal of International Economics, 9(4), 469-479.

Kyle, M. K. (2007) Pharmaceutical price controls and entry strategies. The Review of Economics and Statistics, 89(1), 88-99.

Laffont, J. J. and Tirole, J. (1993) A Theory of Incentives in Procurement and Regulation. Cambridge, M. A.: MIT Press.

Levine, P. and Smith, R. (2000) The arms trade game: from laissez-faire to a common defence policy. Oxford Economic Papers, 52, 357-380.

Levine, P., Mouzakis, F. and Smith, R. (2000). Arms export controls and emerging domestic producers. Defence and Peace Economics, 11, 505-530.

Matraves, C. (1999) Market Structure, R\&D and advertising in the pharmaceutical industry. The Journal of Industrial Economics. XLVII(2), 169-194.

McAfee, R.P. and McMillan, J. (1989) Government procurement and international trade. Journal of International Economics, 26, 291-308.

McGuire, T. and Riordan, M. H. (1995) Incomplete information and optimal market structure. Public purchases from private providers. Journal of Public Economics, 58, 283-307.

Miyagiwa, K. (1991) Oligopoly and discriminatory government procurement policy. American Economic Review, 81, 1321-1328.

NHS procurement review, Cabinet Office 1998. 
Office of Fair Trade (2004) Assessing the impact of public sector procurement on competition. Office of Fair Trade: www.oft.gov.uk.

Pharmaceutical Industry Task Force, Competitiveness and Performance Indicators, 2005. Department of Health: www.advisorybodies.doh.gov.uk/pictf

Vagstad, S. (1995) Promoting fair competition in public procurement. Journal of Public Economics, 58, 283-307.

Vogel, D. (1998) The globalization of pharmaceutical regulation. Governance, 11(1), $1-22$. 